\title{
Clinical characteristics and prognostic factors of posterior segment intraocular foreign body in a tertiary hospital
}

\author{
Jian Ma ${ }^{1,2+}$, Yao Wang ${ }^{1,2+}$, Li Zhang ${ }^{1,2}$, Min Chen ${ }^{1,2}$, Jing Ai ${ }^{1,2}$ and Xiaoyun Fang ${ }^{1,2^{*}}$
}

\begin{abstract}
Background: To identify the clinical characteristics, prognostic factors and visual outcomes in posterior segment IOFBs patients managed by PPV in a tertiary hospital.

Methods: A retrospective chart review was performed for 56 patients, who had PPV for IOFBs removal between November 2013 and November 2015. The mechanisms of injury, the nature of the IOFBs, the BCVA before and after the surgery, the penetrating site and the complications of the surgery were all collected. Univariate analyses were conducted to evaluate the prognostic factors.

Results: The mean age of the patients was 36.4 years. The nature of IOFBs was mainly metal. Most injuries were commonly caused by hammering the metal. The mean preoperative VA was $2.30 \log M A R$, and mean final VA was $0.92 \log$ MAR. From univariate analysis, good visual outcome was correlated with the good visual acuity before surgery and poor visual outcome was correlated with the macular break and multiple surgeries.

Conclusions: In a tertiary hospital of eastern China, most cases of IOFBs were work-related. The prognosis of the patients was really well in the patients with good presenting visual acuity. Nevertheless the prognosis was not good for those patients who had macular injury or underwent several surgeries because of retinal detachment, epiretinal membrane or proliferative vitreous retinopathy. Good facilities for eye protection are urgently in demand for the workers indeed.
\end{abstract}

Keywords: Clinical characteristics, Prognostic factors, Intraocular foreign body

\section{Background}

Open-globe injury often can result in serious visual loss and afflict most patients in the developing country. IOFBs account for $18-41 \%$ of all open-globe injury [1, 2]. Most post-traumatic IOFBs $(58-88 \%)$ reside in the posterior segment [1-4]. The visual prognosis depends on the IOFB size, the zone of the injury, and the accessible treatment [4-6]. Basically IOFBs should be removed from sclera or sclerocorneal tunnel by PPV. Though more techniques have been applied to remove the IOFBs such as "Magnet Handshake" technique [7] and "Macula Protection by Perfluorocarbon Liquid" [8], the prognosis of the patients was not so good in some areas. China is

\footnotetext{
* Correspondence: xiaoyunfang@zju.edu.cn

† Jian Ma and Yao Wang contributed equally to this work.

${ }^{1}$ Eye Center, Second Affiliated Hospital of Zhejiang University School of

Medicine, Hangzhou 310009, China

${ }^{2}$ Zhejiang Provincial Key Lab of Ophthalmology, Hangzhou, China
}

the biggest developing country in the world. During the past twenty years, thousands of factories have sprung up in the east of China. Due to lack of the protection facilities, a lot of workers got hurt at work. Though the injury of the eye could be found immediately after the accident, not all patients sought the treatment timely. The visual outcomes could be totally different whether the patients would consult the doctor in time or not. With advancement in the microsurgical technique, those severely traumatized eyes can be saved from enucleation. However, some patients received several surgeries and still could not save their sight. The objectives of this study were to identify the clinical characteristics and prognostic factors in posterior segment IOFBs patients managed by 23-gauge PPV in the east of china.

(c) The Author(s). 2019 Open Access This article is distributed under the terms of the Creative Commons Attribution 4.0 International License (http://creativecommons.org/licenses/by/4.0/), which permits unrestricted use, distribution, and reproduction in any medium, provided you give appropriate credit to the original author(s) and the source, provide a link to the Creative Commons license, and indicate if changes were made. The Creative Commons Public Domain Dedication waiver (http://creativecommons.org/publicdomain/zero/1.0/) applies to the data made available in this article, unless otherwise stated. 


\section{Methods}

The patients who were diagnosed with IOFBs at The Second Affiliated Hospital of Zhejiang University School of Medicine between November 2013 and November 2015 were included for this study. The follow-up ended up with the patients' last control. The study was approved by Institutional Review Board of Second Affiliated Hospital of Zhejiang University School of Medicine and conducted in compliance with guidelines of the Declaration of Helsinki. The complete history of the patients was taken at their first presentation. The initial BCVA of the patient was recorded using the Snellen chart. It was converted to a logMAR units for statistical analysis. An anterior segment ophthalmologic examination was performed with a slit-lamp (BQ 900; Haag-Streit, Berne,Switzerland). The location of the metallic IOFB was identified by a computerized tomography before operation. The collected data comprised age, gender, mechanism of injury, preoperative VA, initial ocular features, nature of foreign bodies, time interval between injury and IOFBs removal, postoperative VA and complications. All patients with a leaking wound underwent primary wound repair by general ophthalmologists before IOFBs removal surgery. Patients with a self-sealing wound underwent PPV surgery for the initial intervention. A classic three-port, 23-gauge vitrectomy technique was performed by three retinal specialists (J.M., Y.W. and L.Z.). The non-contact wide-angle vitreous surgery system was used during the PPV surgery. The corneal entry site was sutured with Nylon $10-0$ and the scleral wound was repaired with Vicryl $8-0$. If the view for performing the PPV surgery was obstructed by the traumatic cataract, a lensectomy or phacoemulsification procedure was also done during the surgery. The intraocular lens was not implanted for the first time. IOFBs were removed from the enlarged sclerotomy or limbal incision either with the intraocular forceps or the external magnet. The injured retinal areas, including retinal holes or detached retina were secured by endolaser photocoagulation, cryoretinopexy. Either gas or silicone oil was used for the intraocular tamponade. The patients were regularly controlled by the retinal experts of the Second Affiliated Hospital of Zhejiang University School of Medicine. A PMMA lens with iris fixation was implanted in the anterior chamber or a single-piece PMMA lens was implanted into the ciliary sulcus depending on the integrity of the lens capsule after 3 months. In addition, vitreoretinal operations were performed in case of complications, such as retinal detachment or macular pucker. A good visual outcome was defined as the final BCVA equal to or better than 20/40. A poor visual outcome was determined as final BCVA of less than $20 / 200$.

\section{Statistical analysis}

Statistical analysis of data was performed using SPSS 17.0 (SPSS Inc., Chicago, IL). Continuous data were reported as mean \pm standard deviation, and categorical data were reported as $\mathrm{n}(\%)$. Paired sample $t$-test and chi-square test were used for comparing the preoperative BCVA to the postoperative BCVA. The predictive factors for visual outcomes were studied using univariate analysis (Fisher exact test, or Mann-Whitney U-test). A $P$ value of 0.05 was considered statistically significant in this study.

\section{Results}

Of the referred to our center for ocular trauma associated with IOFBs between November 2013 and November 2015, 56 patients were included for this study. The mean follow-up time was 15.6 months (range 9-36, median 13.5, SD 4.7 months) and mean age was 40.8 years (range 8-63, median 40.5, SD 12.9 years). Fifty-four (54/ $56,96.4 \%)$ patients were male. In all, 54 (54/56, 96.4\%) patients were work-related. The nature of the IOFBs was metal in $54(54 / 56,96.4 \%)$ patients, glass in $1(1 / 56$, $1.8 \%)$ patient and wood in $1(1 / 56,1.8 \%)$ patient. The mechanisms of injury and the nature of the intraocular foreign body are summarized in Table 1 and Table 2 . The mean preoperative VA was 2.30 (range 0.00-3.00, median 2.70, SD 0.90) logMAR. The penetrating sites were from cornea $(37 / 56,66.1 \%)$, sclera $(11 / 56,19.6)$ and corneosclera $(8 / 56,14.3 \%)$ (Table 3$)$. The preoperative clinical data of the patients are presented in Table 4. More than half of the patients $(42 / 56,75 \%)$ had lens injury. Retinal injury including retinal break, retinal hemorrhage and retinal detachment were seen from 46 patients (46/56, 82.1\%). 12 patients (12/56, 21.4\%) developed into endophthalmitis because of untreated penetrating site or delayed visiting the doctor. One patient was afflicted by siderosis bulbi $(1 / 56,1.8 \%)$.

Table 1 Mechanisms of injury

\begin{tabular}{ll}
\hline Mechanism of injury & Number (\%) \\
\hline Hammering the metal & $33(58.9)$ \\
Using electric drill & $5(8.9)$ \\
Shaving steel wire & $4(7.1)$ \\
Air nail gun & $3(5.4)$ \\
Chiseling on metal & $3(5.4)$ \\
Looking at others' working & $3(5.4)$ \\
Firework explosion & $1(1.8)$ \\
Wood cutting & $1(1.8)$ \\
Stabbed by the pencil & $1(1.8)$ \\
Hit by the branch & $1(1.8)$ \\
Electric welding & $1(1.8)$ \\
\hline
\end{tabular}


Table 2 The nature of the intraocular foreign body

\begin{tabular}{ll}
\hline Nature of the foreign body & Number(\%) \\
\hline Magnetic Metal & $52(92.9)$ \\
Gun nail & $2(3.6)$ \\
Wood & $1(1.8)$ \\
Glass & $1(1.8)$ \\
\hline
\end{tabular}

Lens removal was performed with either phacoemulsification or pars plana lensectomy at the time of vitrectomy in $42(42 / 56,75 \%)$ patients. Intraocular tamponade was performed at the end of surgery in $52(52 / 56$, $92.90 \%)$ patients. Of these, $25(25 / 52,48.10 \%)$ were silicone oil and $27(27 / 52,51.90 \%)$ gas tamponade. At the end of follow-up, $4(4 / 56,7.14 \%)$ patients had failed to achieve anatomical success with no light perception. The main reasons for this were severe proliferative vitreous retinopathy and macular injury. Anatomical success was achieved in 52 (52/56, 92.90\%) patients.

The mean final BCVA was 0.92 (range 0.00-3.00, median 0.40, SD 1.03) logMAR. Four (4/56, 7.1\%) patients reported no light perception after IOFBs removal. The final BCVA was improved in $44(44 / 56,78.57 \%)$ patients, stabilized in $8(8 / 56,14.29 \%)$ and worse in $4(4 / 56$, $7.14 \%)$. Preoperative and final visual acuities were demonstrated in Table 5 and Fig. 1. Almost forty-eight (48/ $56,85.7 \%$ ) patients had low vision (less than $20 / 200$ ) before surgery. More than forty-three (43/56, 76.8\%) patients got the good vision (better than 20/200). Postoperative improvement of visual acuity was statistically significant $(P=0.008)$. The large IOFB would be removed from the limbal incision. A $30 \mathrm{~mm} \mathrm{IOFB} \mathrm{was}$ removed from the limbal incision of the patient. The final visual acuity of the patient was surprisingly 20/40 (Fig. 2).

For good visual outcome, univariate analysis showed that good presenting VA (Fisher exact test, $P=0.005$ ) was the significant associated predictors (Table 6). There was no statistical significance for the patients with different entry site, with lens injury, retinal injury and endophthalmitis or not.

For poor visual outcome, univariate analysis showed that presence of macular break and undergoing multiple vitrectomy (Fisher exact test, $P=0.006,0.0001$ ) were the significant associated predictors (Table 7). No statistical significance was seen from the patients with different

Table 3 Penetrating site of the patients

\begin{tabular}{ll}
\hline Clinical characteristics & Number (\%) \\
\hline Cornea & $37(66.1)$ \\
Sclera & $11(19.6)$ \\
Corneosclera & $8(14.3)$ \\
\hline
\end{tabular}

Table 4 Clinical data of the patients

\begin{tabular}{ll}
\hline Clinical characteristics & Number (\%) \\
\hline Hyphema & $5(8.9)$ \\
Iris injury & $2(3.6)$ \\
Lens injury & $42(75)$ \\
Vitreous hemorrhage & $20(35.7)$ \\
Retinal injury & \\
Retinal break & $20(35.7)$ \\
Retinal hemorrhage & $19(33.9)$ \\
Retinal detachment & $7(12.5)$ \\
Endophthalmitis & $12(21.4)$ \\
Siderosis bulbi & $1(1.8)$ \\
\hline
\end{tabular}

initial VA and entry site, with lens injury, retinal injury and endophthalmitis or not.

\section{Discussion}

In the developing country, IOFBs is a serious problem in a young working age population. In accordance with previous reports [5,9-11], our study showed that the majority of patients $(96.4 \%)$ were male, with a mean age of 40.8 years. This study found that $91.1 \%$ of the patients had work-related injury. Metal was the most common nature of IOFBs, accounting for $96.4 \%$ of the patients, which is similar to the other studies [4, 12, 13]. This study also revealed that the hammering the metal was the most common mechanism of injury (58.9\%), same as the other study in china [14]. It is different from in Thailand, where the electric grass trimmer was the most common mechanism of injury [15].

There are several tools to remove the IOFBs, including external magnets, intraocular magnets and foreign body claw. Pars plana vitrectomy can be the first choice for the patients with the IOFBs in the posterior segment, though magnetic suction from the sclera is still used in the non-developed areas. With advancement of the surgical facilities and the techniques, 23-gauge vitrectomy was commonly recommended for the posterior IOFBs on account of the less damages and rapid recovery [16]. Sometimes 25-gauge vitrectomy was also used in some cases. However, 25-gauge PPV is not necessary for the patient with large IOFBs. The IOFBs are usually extracted from the corneoscleral limbus or the sclera. It

Table 5 Preoperative and final visual acuity

\begin{tabular}{lll}
\hline VA & Preoperative VA N (\%) & Final VA N (\%) \\
\hline$>=20 / 40$ & $5(8.9)$ & $21(37.5)$ \\
$<20 / 40-20 / 200$ & $3(5.4)$ & $22(39.3)$ \\
$<20 / 200$ & $48(85.7)$ & $13(23.2)$ \\
Total & $56(100)$ & $56(100)$
\end{tabular}

Abbreviation: VA visual acuity 


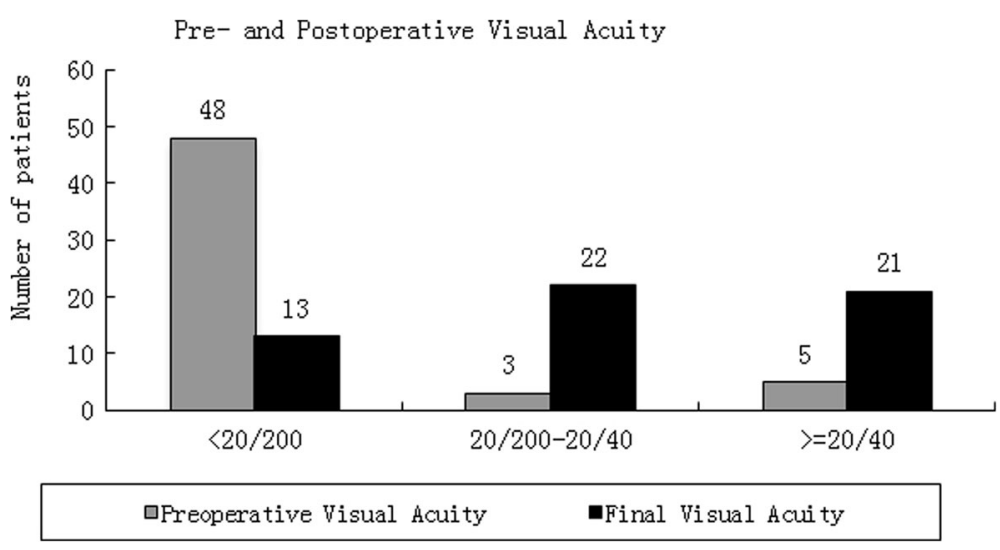

Fig. 1 Pre- and Postoperative Visual Acuity. The grey columns showed the pre-operative visual acuity of the patients. The black columns showed the postoperative visual acuity. Almost forty-eight patients had low vision (less than 20/200) before surgery. More than forty-three patients got the good vision after surgery (better than 20/200)

depends on the size of the IOFBs and integrity of the lens. Usually the IOFBs will be removed from the corneoscleral limbus if their diameters are more than $6 \mathrm{~mm}$. For the small ones, the IOFBs can be taken out from the limbus or sclera. We would like to choose the limbus if the patients were diagnosed with traumatic cataract.

We found that good presenting VA before surgery was a significant associated predictor for the good visual outcome. This is the same as the previous reports $[10,17]$. But the other study claimed that the initial BCVA was not the best reliable predictive factor for the final BCVA by the multiple correspondence analyses [18].
Poor presenting VA has previously been reported as an important predictive factor for poor visual outcomes [18]. However, our study showed that most patients (35/ 48) with the initial VA less than $20 / 200$ had better final VA (better than 20/200). It is reasonable that the patients had low presenting VA if the patients suffered traumatic cataract and vitreous hemorrhage. The VA can be improved greatly with cataract extraction and vitreous hemorrhages removal if the macular of the patients remained integrity. Unfortunately the patients had low final VA when they had macular break. Others also reported that the most relevant parameters for a low final
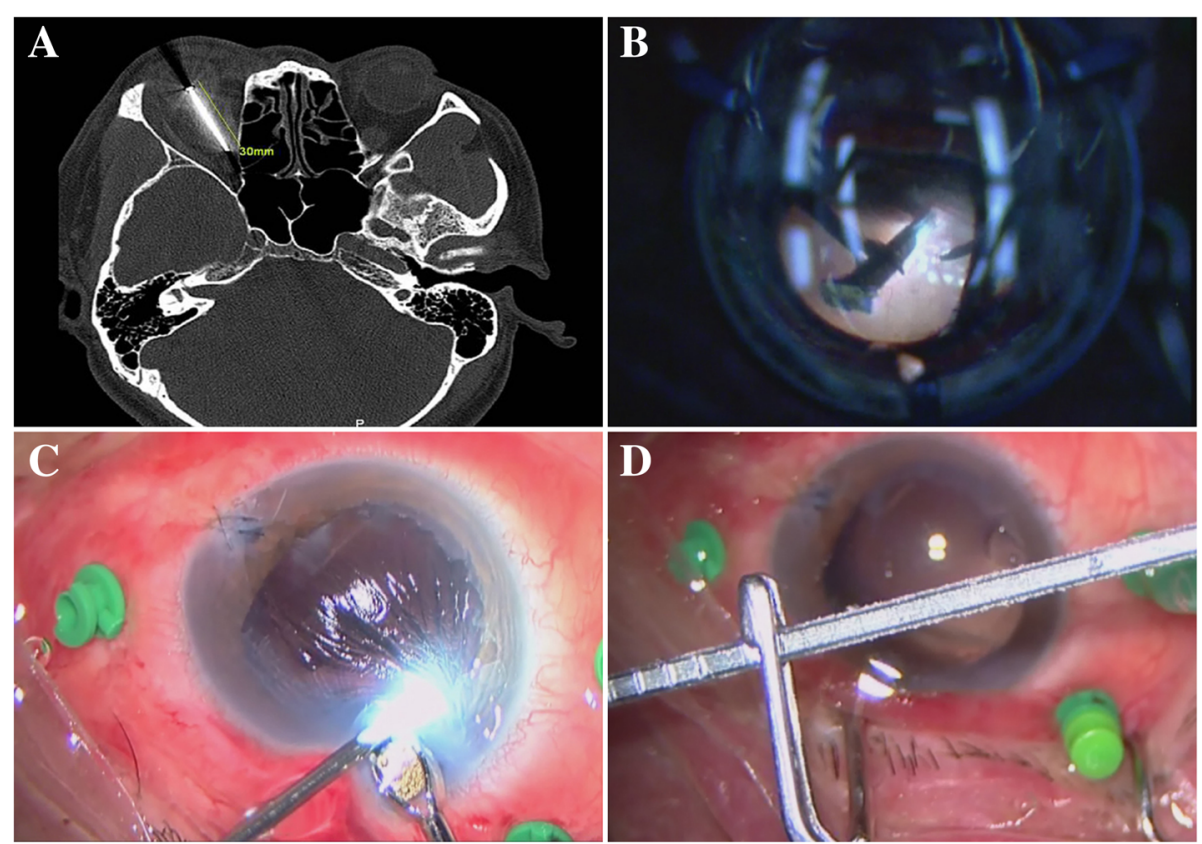

Fig. 2 A large IOFB was removed from the limbal incision. a: The orbital CT scan of the patient. b: Grabbing the IOFB with the intraocular forceps. c: Removing the IOFB from the limbal incision. $\mathbf{d}$ : The whole view of the IOFB in the microscope 
Table 6 Univariate analysis: predictors for good visual outcome

\begin{tabular}{llll}
\hline Predictive factors & Final VA & Final VA & $P$-value \\
& $\begin{array}{l}>=20 / 40 \\
N(\%)\end{array}$ & $\begin{array}{l}<20 / 40 \\
\mathrm{~N}(\%)\end{array}$ & \\
\hline Mean age (years) & 38.5 & 40 & 0.388 \\
Sex (male: female) & $20: 1$ & $34: 1$ & 0.614 \\
Initial VA > =20/40 & $5(100)$ & 0 & 0.005 \\
Entry site & & & \\
Cornea & $11(29.7)$ & $26(70.3)$ & 0.145 \\
Sclera & $5(45.5)$ & $6(54.5)$ & 0.730 \\
Corneosclera & $5(62.5)$ & $3(37.5)$ & 0.136 \\
Lens injury & $14(33.3)$ & $28(66.7)$ & 0.343 \\
Retinal injury & & & \\
Break & $6(30)$ & $14(70)$ & 0.565 \\
RD & $1(14.3)$ & $6(85.7)$ & 0.237 \\
Hemorrhage & $7(36.8)$ & $12(63.2)$ & 0.589 \\
Endophthalmitis & $5(41.7)$ & $7(58.3)$ & 0.493 \\
\hline
\end{tabular}

Abbreviations: $R A P D$ relative afferent pupillary defect, $R D$ rhegmatogenous retinal detachment, $V A$ visual acuity

${ }^{a}$ Mann-Whitney U-test; in others Fisher exact test was used

BCVA were the presence of a macular lesion [18], RD at presentation and large foreign body [19]. The prognosis was also not good for those patients had several surgeries because of retinal detachment, epiretinal membrane or proliferative vitreous retinopathy. It is due to delayed return visit or a long wait-list for the surgery.

Table 7 Univariate analysis: predictors for poor visual outcome

\begin{tabular}{llll}
\hline Predictive factors & $\begin{array}{lll}\text { Final VA } \\
<20 / 200\end{array}$ & $\begin{array}{l}\text { Final VA } \\
>=20 / 200\end{array}$ & \\
& $\mathrm{~N}(\%)$ & $\mathrm{N}(\%)$ & \\
\hline Mean age (years) & 39.1 & 41.3 & $0.748^{\mathrm{a}}$ \\
Sex (male: female) & $13: 0$ & $41: 2$ & 0.586 \\
Initial VA < 20/200 & $13(27.1)$ & $35(72.9)$ & 0.349 \\
Entry site & & & \\
Cornea & $7(18.9)$ & $30(81.1)$ & 0.128 \\
Sclera & $4(36.4)$ & $7(63.6)$ & 0.195 \\
Corneosclera & $2(25)$ & $6(75)$ & 0.685 \\
Lens injury & $8(19)$ & $34(81)$ & 0.080 \\
Retinal injury & & & \\
Break & $8(40)$ & $12(60)$ & 0.105 \\
RD & $4(57.1)$ & $3(42.9)$ & 0.058 \\
Hemorrhage & $8(42.1)$ & $11(57.9)$ & 0.051 \\
Endophthalmitis & $3(25)$ & $9(75)$ & 0.658 \\
Macular Break & $4(100)$ & $0(0)$ & 0.006 \\
Multiple Vitrectomy & $7(87.5)$ & $1(12.5)$ & 0.0001 \\
\hline
\end{tabular}

Abbreviations: $R A P D$ relative afferent pupillary defect, $R D$ rhegmatogenous retinal detachment, $V A$ visual acuity. ${ }^{a}$ Mann-Whitney U-test; in others Fisher exact test was used
Previous study showed that presence of endophthalmitis, relative afferent pupillary defect (RAPD) and initial $\mathrm{RD}$ was the significant associated predictors for the poor final VA [15]. Our study showed the different results. Among 12 patients diagnosed with endophthalmitis, only 3 patients had the low final VA less than 20/200. There is no statistical difference between the final VA less than 20/200 group and the final VA better than 20/ 200 group. RAPD was not included for this study since some patients had anterior chamber hemorrhages and iris injuries. Initial RD was not the significant predictive factor for the poor final VA in our study. If the detached retina was reattached before the macular was involved, the final VA could be better. Recent study revealed that early removal of IOFB may related to the favourable visual outcome and low endophthalmitis [20]. It means the patient could have a higher chance to recover better if they got the timely treatment.

\section{Conclusions}

In conclusion, most cases of IOFBs were work-related in a tertiary hospital located in the east of china. The prognosis of the patients was really good with good presenting visual acuity. Nevertheless the prognosis was not good for those patients who had macular injury or underwent several surgeries because of retinal detachment, epiretinal membrane or proliferative vitreous retinopathy. Good facilities for eye protection are urgently in demand for the workers indeed.

\section{Abbreviations}

BCVA: Best corrected visual acuity; CT: Computerized tomography;

IOFBs: Intraocular foreign bodies; logMAR: Logarithm of the minimal angle of resolution; PPV: Pars plana vitrectomy; VA: Visual acuity

Acknowledgments

Thanks to Dr. Yan Wen and Xin Xie for the clinical help.

\section{Funding}

This Project was supported by NSFC (Natural Science Foundation of China) (No. 81571819 \& 81500766) and Natural Science Foundation of Zhejiang Province, China (No. LY14H120004 \& No.LQ14H120001). The funding body had no role in the construct of this manuscript.

\section{Availability of data and materials}

The datasets used and analyzed during the current study are available from corresponding author on reasonable request.

\section{Author's contributions}

Authors' contributions: JM, YW and LZ performed the surgery, analyzed the patient data and made major contributions for writing the manuscript. MC and JA performed the literature review for similar topics and made major contributions to acquisition and interpretation of data. XY-F made substantial contributions to conception and design this study. All authors have read and approved the final manuscript.

\section{Ethics approval and consent to participate}

This study was approved by the research ethics committee of The Second Affiliated Hospital of Zhejiang University School of Medicine. Due to the retrospective nature of this study, the inform consent from individual patient was waived by IRB in this study. 


\section{Consent for publication}

Not Applicable.

\section{Competing interests}

The authors declare that they have no competing interests.

\section{Publisher's Note}

Springer Nature remains neutral with regard to jurisdictional claims in published maps and institutional affiliations.

Received: 16 October 2018 Accepted: 28 December 2018 Published online: 14 January 2019

\section{References}

1. Patel SN, Langer PD, Zarbin MA, et al. Diagnostic value of clinical examination and radiographic imaging in identification of intraocular foreign bodies in open globe injury. Eur J Ophthalmol. 2012;22(2):259-68.

2. Zhang $Y$, Zhang $M$, Jiang $C$, et al. Intraocular foreign bodies in China: clinical characteristics, prognostic factors, and visual outcomes in 1,421 eyes. Am J Ophthalmol. 2011;152(1):66-73.e1.

3. Szijarto Z, Gaal V, Kovacs B. Prognosis of penetrating eye injuries with posterior segment intraocular foreign body. Graefes Arch Clin Exp Ophthalmol. 2008;246:161-5.

4. Woodcock MG, Scott RA, Huntbach J, et al. Mass and shape as factors in intraocular foreign body injuries. Ophthalmology. 2006;113(12):2262-9.

5. Jonas JB, Knorr HL, Budde WM. Prognostic factors in ocular injuries caused by intraocular or retrobulbar foreign bodies. Ophthalmology. 2000;107(5):823-8.

6. Knyazer B, Levy J, Rosen S, et al. Prognostic factors in posterior open globe injuries (zone-III injuries). Clin Exp Ophthalmol. 2008;36(9):836-41.

7. Dhoble P, Khodifad A. Combined cataract extraction with pars Plana vitrectomy and metallic intraocular foreign body removal through Sclerocorneal tunnel using a novel "magnet handshake" technique. Asia Pac J Ophthalmol (Phila). 2017; [Epub ahead of print]

8. Rejdak R, Choragiewicz T, Moneta-Wielgos J, et al. Intraoperative macula protection by perfluorocarbon liquid for the metallic intraocular foreign body removal during 23-gauge vitrectomy. J Ophthalmol. 2017;2017: 6232151 Epub 2017 May 2

9. Wickham L, Xing W, Bunce $C$, et al. Outcomes of surgery for posterior segment intraocular foreign bodies-a retrospective review of 17 years of clinical experience. Graefes Arch Clin Exp Ophthalmol. 2006;244(12):1620-6.

10. Greven C, Engelbrecht N, Slusher M, et al. Intraocular foreign bodies: management, prognostic factors. and visual outcomes Ophthalmology. 2000;107(3):608-12.

11. Szurman P, Roters $S$, Grisanti $S$, et al. Primary silicone oil tamponade in the management of severe intraocular foreign body injuries: an 8-year followup. Retina. 2007;27(3):304-11

12. Demircan $N$, Soylu M, Yagmur $M$, et al. Pars plana vitrectomy in ocular injury with intraocular foreign body. J Trauma. 2005;59(5):1216-8.

13. Ehlers J, Kunimoto D, Ittoop S, et al. Metallic intraocular foreign bodies: characteristics, interventions, and prognostic factors for visual outcome and globe survival. Am J Ophthalmol. 2008;146(3):427-33.

14. Zhang $Y$, Zhang $M$, Jiang $C$, et al. Intraocular foreign bodies in China: clinical characteristics, prognostic factors, and visual outcomes in 1421 eyes. Am J Ophthalmol. 2011 Jul;152(1):66-73.e1.

15. Choovuthayakorn J, Hansapinyo L, Ittipunkul N, et al. Predictive factors and outcomes of posterior segment intraocular foreign bodies. Eye (Lond). 2011; 25(12):1622-6

16. Yuksel K, Celik U, Alagoz C, et al. 23 gauge pars plana vitrectomy for the removal of retained intraocular foreign bodies. BMC Ophthalmol. 2015;15:75.

17. Wani VB, Al-Ajmi M, Thalib $L$, et al. Vitrectomy for posterior segment intraocular foreign bodies: visual results and prognostic factors. Retina. 2003;23:654-60.

18. Valmaggia C, Baty F, Lang C, et al. Ocular injuries with a metallic foreign body in the posterior segment as a result of hammering: the visual outcome and prognostic factors. Retina. 2014;34(6):1116-22.

19. Nicoară SD, Irimescu I, Călinici T, et al. Intraocular foreign bodies extracted by pars plana vitrectomy: clinical characteristics, management, outcomes and prognostic factors. BMC Ophthalmol. 2015:15:151.

20. Liu CC, Tong JM, Li PS, et al. Epidemiology and clinical outcome of intraocular foreign bodies in Hong Kong: a 13-year review. Int Ophthalmol. 2017;37(1):55-61.

Ready to submit your research? Choose BMC and benefit from:

- fast, convenient online submission

- thorough peer review by experienced researchers in your field

- rapid publication on acceptance

- support for research data, including large and complex data types

- gold Open Access which fosters wider collaboration and increased citations

- maximum visibility for your research: over $100 \mathrm{M}$ website views per year

At $\mathrm{BMC}$, research is always in progress.

Learn more biomedcentral.com/submissions 